\title{
"Not Resembling" in Ni Zan's Landscape
}

\section{Hao Cao}

Hubei Fine Arts Publishing House, Wuhan 430070, Hubei, China

DOI: $10.32629 /$ asc.v2i4.560

\begin{abstract}
This essay will discuss the extent to which Ni Zan puts "not resembling" into practice in his landscape paintings, considering the modular aspects of Ni Zan's work. Firstly, the compositions depicted in Ni's and later imitators' work will be analyzed and compared. Then, the brushworks of Ni will be closely observed by selecting individual objects from several paintings. And finally, the author engages with textual research on Ni's painting theories.
\end{abstract}

Keywords: landscape painting, China, art history, Ni Zan

\section{Introduction}

In the year 1271, the mongol regime successfully seized political power of the Sung government by armed force and established the Yuan dynasty. As a result, the scholars and literati of the Sung dynasty suffered class, economic and political oppression. In this arduous circumstance, many literary paintings suggest an escape from the abyss of misery to live in seclusion. Ni Zan (1301-1374) who born in a wealthy Taoist family, is known as one of The Four Masters of the Yuan dynasty. He concealed the turbulence of life inside his distinct works and achieved the quintessence of the term bu-si, which literally means "not resembling". In a letter to his friend Zhang Zaozhong, Ni wrote: "... What I call painting is merely sketching with a few untrammelled brushstrokes. I never seek for formal likeness, because I paint only for my own amusement." This creative suggestion was highly appreciated and imitated by the later literati in the Ming and Qing period. In this essay, I will discuss the extent to which Ni Zan puts "not resembling" into practice in his landscape paintings, considering, the modular aspects of Ni Zan's work: firstly, I will analyse and compare the compositions depicted in Ni's and later imitators' work; then, I will closely observe the brushworks of $\mathrm{Ni}$, by selecting individual objects from several paintings; and finally, I engage with textual research on Ni's painting theories.

\section{The concept of modular}

Ni Zan's paintings are reputed to be modular: for example there may be a composition of one river and two separate riverbanks and repeated objects. Typically, examples can be found in works from his later phase: River Pavilion, Mountain Colours (Figure 1) and The Rongxi Studio (Figure 2). These two representative paintings are composed of three similar parts: (1) a feeble and pale riverbank is settled in the foreground of the scene, reinforced with several sketched-style rocks; a small amount of withered trees grow upwards from the infertile soil yet the types of them are illegible; a deserted pavilion is rendered in succinct brushworks arranged in a blank area. (2) the middle empty part is a fairly broad lake surface almost without any ripples, which creates a motionless atmosphere, and (3) the lake is stretched away to the distant horizon with low mountains solitarily situated at the background of the painting and set off with a vast expanse of open sky with inscriptions. This unique formation appears in Ni Zan's works again and again and therefore can be regarded as his fully developed style. and the objects that appear in this formation-the empty pavilion, the expanse of water and the bleak trees - are considered to be symbols of his painting.

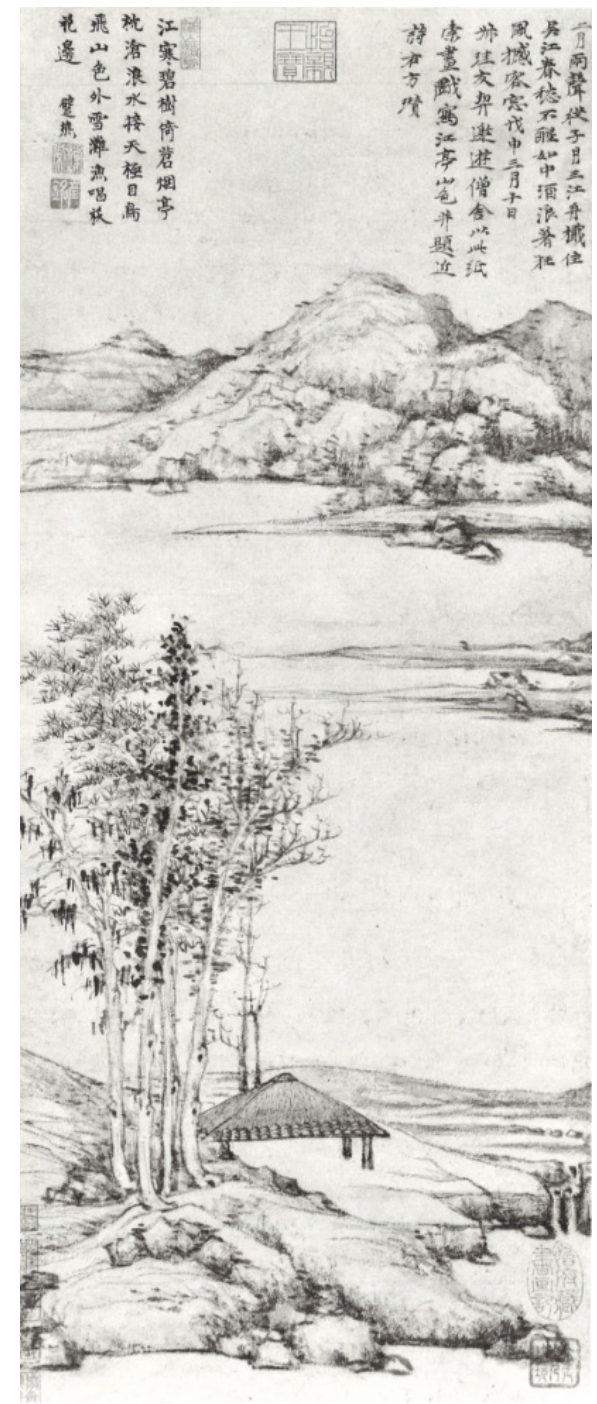

Figure 1. Ni Zan. River Pavilion, Mountain Colors (Dated 1368; Hanging scroll, ink on paper, $81.6 \times 33.4 \mathrm{~cm}$; Asian Art Museum of San Francisco) 


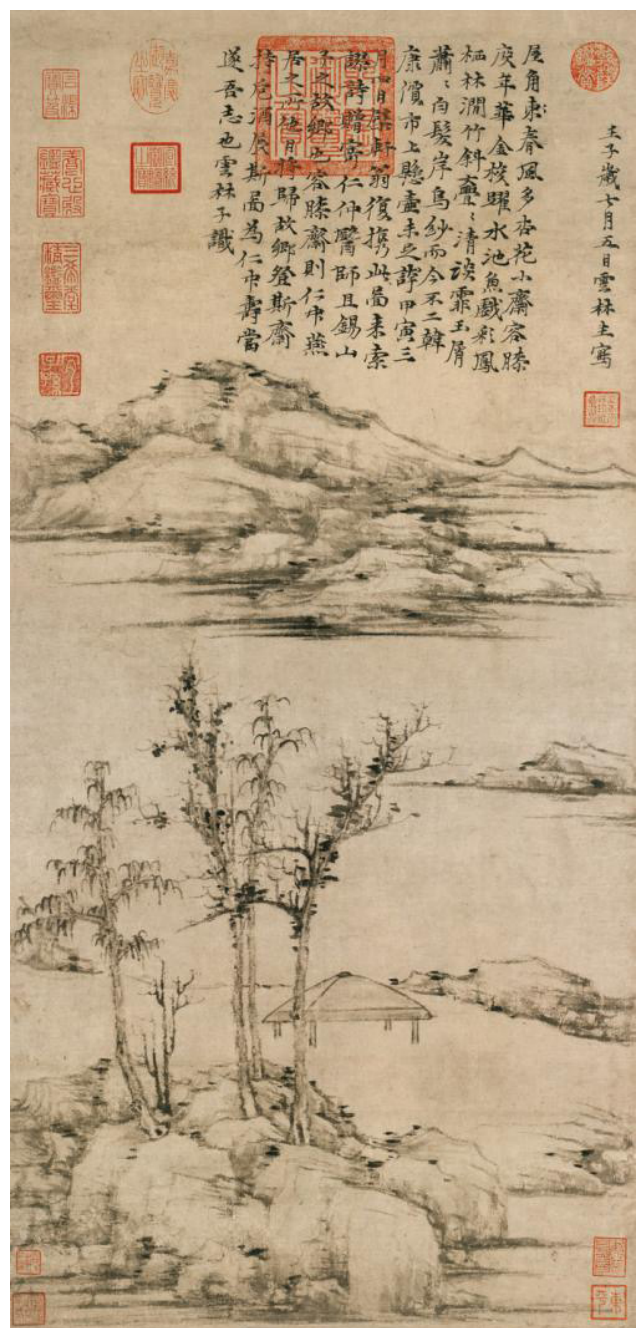

Figure 2. Ni Zan, The Rongxi Studio (Dated 1372; Handscroll, ink on paper, $74.7 \times 35.5 \mathrm{~cm}$; National Palace Museum, Taipei)

The evidence of this conception is that the majority of paintings in imitation of Ni Zan's style in the Ming and Qing periods represent these distinguishing features, such as Saying Farewell: In the Style of Ni Zan (Figure 3) by Shen Zhou (1427-1509) and Landscape in the Style of Ni Zan (Figure 4) by Wang Yuanqi (1642-1715). In these two paintings, it is significant that the rocks are reinforced by folded-belt texture strokes and that there is an empty pavilion beside a clustered trees. There are 33 paintings in the style of Ni Zan attributed to Shen Zhou, nine of which have been definitively proven by Chinese painting institutions. The composition of the nine works are in the three-part form, and most of them depict separated riverbanks, regardless of the reality of the places, seasons and events which they were depicting. This means the modularity of Ni Zan's painting was acquiesced in the later literati's conscious minds. In this case, it could be said that the literal representation of place in Ni Zan's paintings were inconsequential to himself and to his imitators. It is not possible to depict a variety of landscapes by only one modular design. For this reason, Ni Zan presumably ignored whether his paintings showed likeness or not in order to show this variety.

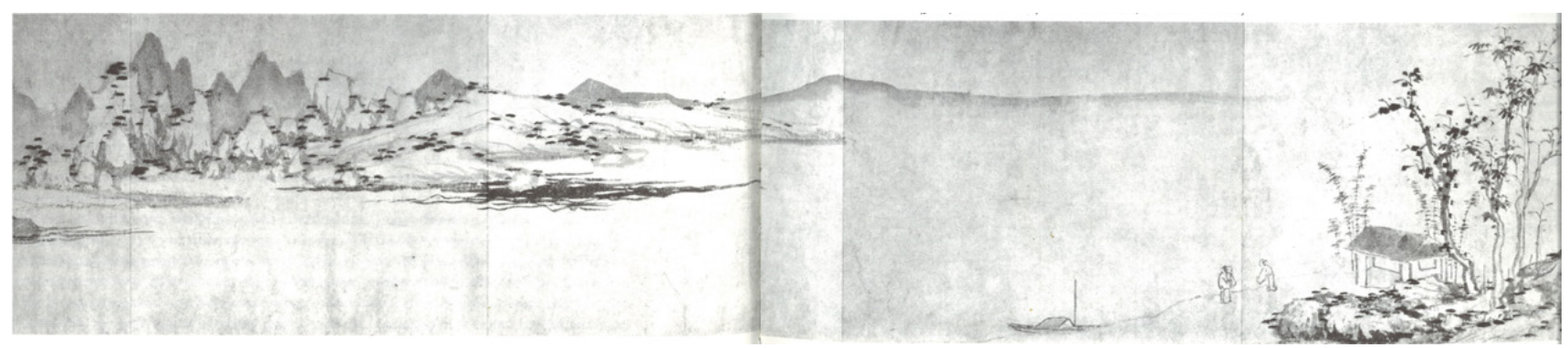

Figure 3. Shen Zhou, Saying Farewell: In the Style of Ni Zan

(Undated, ca.1500; Handscroll, ink on paper; The Art Museum, Princeton University) 


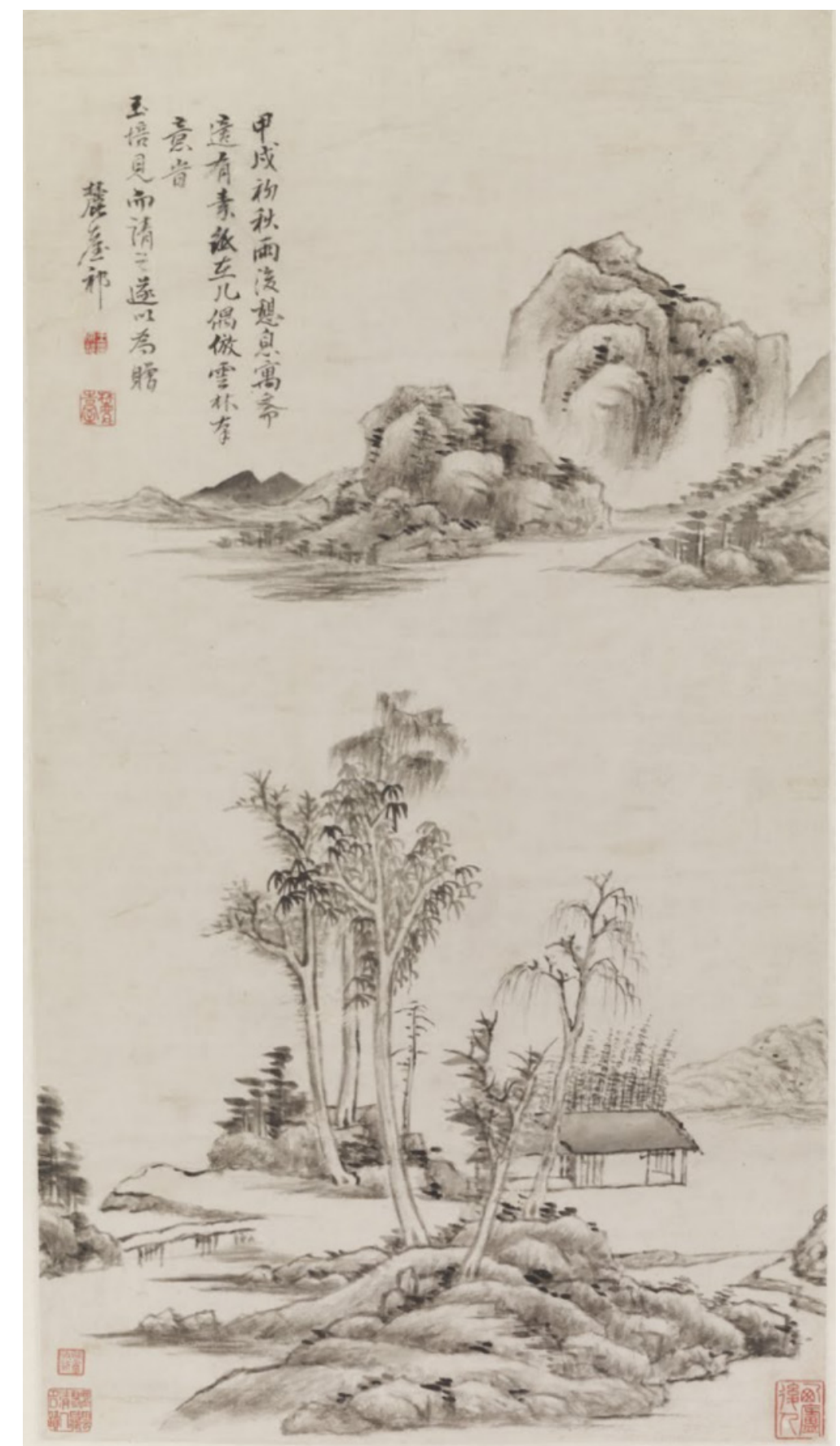

Figure 4. Wang Yuanqi, Landscape in the Style of Ni Zan (Dated 1694; Handscroll, ink on paper; Freer and Sackler Galleries)

To prove the lack of relatively between reality and the paintings of Ni Zan, the inscriptions of his works should also be noted. According to James Cahill, most of Ni's painting are "occasional creations", created "spontaneously" for his friends and hosts at gatherings during the refugee's life. The circumstances and contents of the productions are usually introduced in the inscriptions. The dedication and title of Ni's representative work The Rongxi Studio (Figure 2) suggests it should be a scene of the Rongxi Studio, but instead of a lodge, as might be expected, there is a small empty pavilion in the painting. It is likely that Ni often added a title and inscription later, even a long time after he finished the work. Autumn Clearing over a Fishing Lodge (Figure 5) is a characteristic example: produced in 1355, Ni made the inscription in 1372. Another similar landscape, Wind Among the Trees on the Riverbank, is dated 1363 but the content of the inscription is completely different: $\mathrm{Ni}$ writes a poem to cherish the memory of his wife Jiang Yuanming who passed away at the beginning of that year. This is to say, the content of the inscription and that of the painting are normally independent of each other, which reflects the "not resembling" in Ni Zan's works. 


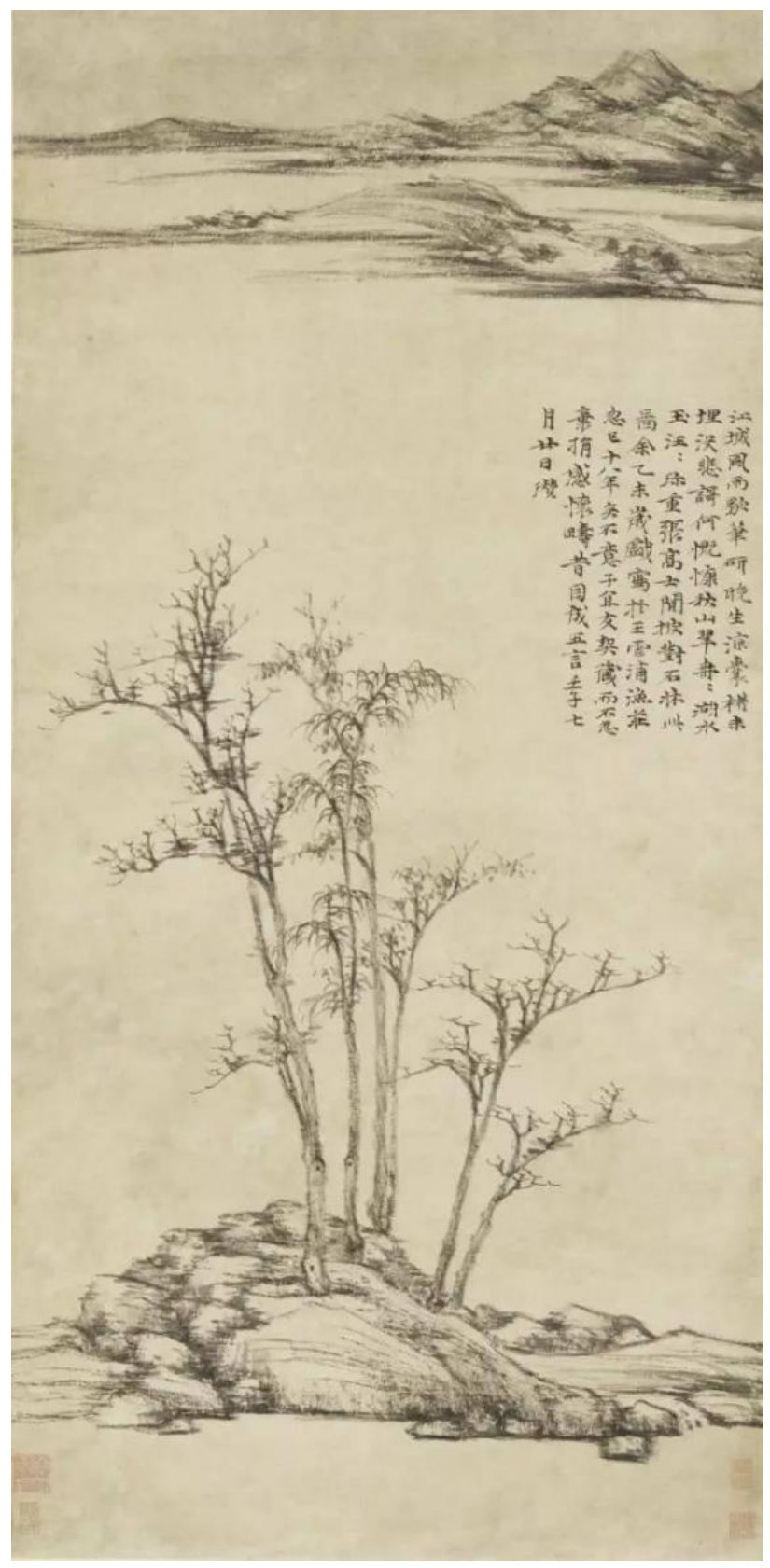

Figure 5. Ni Zan, Autumn Clearing over a Fishing Lodge

(Inscription of 1372 gives date as 1355; Hanging scroll, ink on paper, $97 \times 47 \mathrm{~cm}$; Shanghai Museum)

\section{Beyond representation}

However, if thinking about the change in Ni Zan's living environment, then defining his paintings as "modular" would be questionable. Enjoying the Wilderness in an Autumn Grove, dated 1339 (Figure 6), as well as Water and Bamboo Dwelling, dated 1343 (Figure 7), do not show the typical formation. The possible reason of this difference is that extremely high taxes and natural disasters ended Ni's era of fortune in the 1340s, thus he led a refugee's life around the area of Lake Tai beginning in 1356. Considering the scenery of Lake Tai, it is reasonable to interpret Ni's repeated landscapes as being based on reality rather than on a dream; the "one river, two banks" scheme ought to be considered as the most optimal way he chose to represent the Lake Tai. Therefore, to curtly use the word "modular" to summarise the composition of Ni Zan's paintings is thoughtless; since the motive of the composition is not to meld unfounded and independent objects so that fabricate a fantasy inner-world. Dong Qichang (1555-1636) intentionally captures Ni's formation when he represents the view of Lake Lian in Hermitage dated 1617 (Figure 8). This echos the classic composition of Ni's painting, albeit from a different perspective, that verily resembles Lake Tai. 


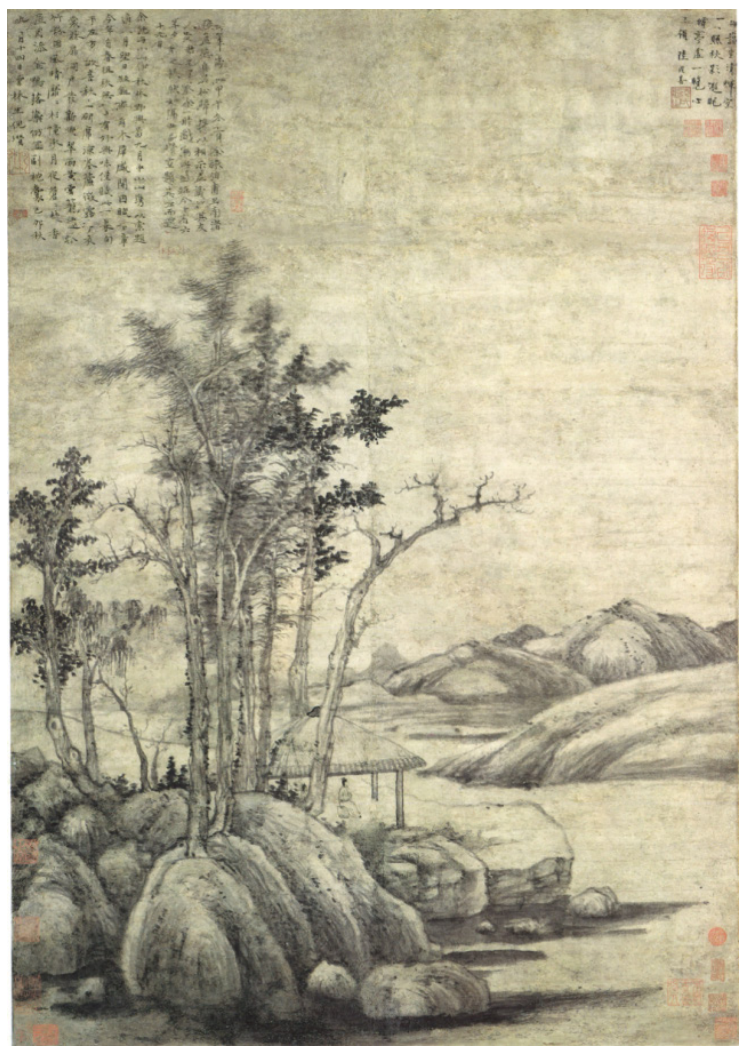

Figure 6. Ni Zan. Enjoying the Wilderness in an Autumn Grove

(Dated 1339; Hanging scroll, ink on paper, $97 \times 68.5 \mathrm{~cm}$; Bequest of John M. Crawford, Jr., 1988)

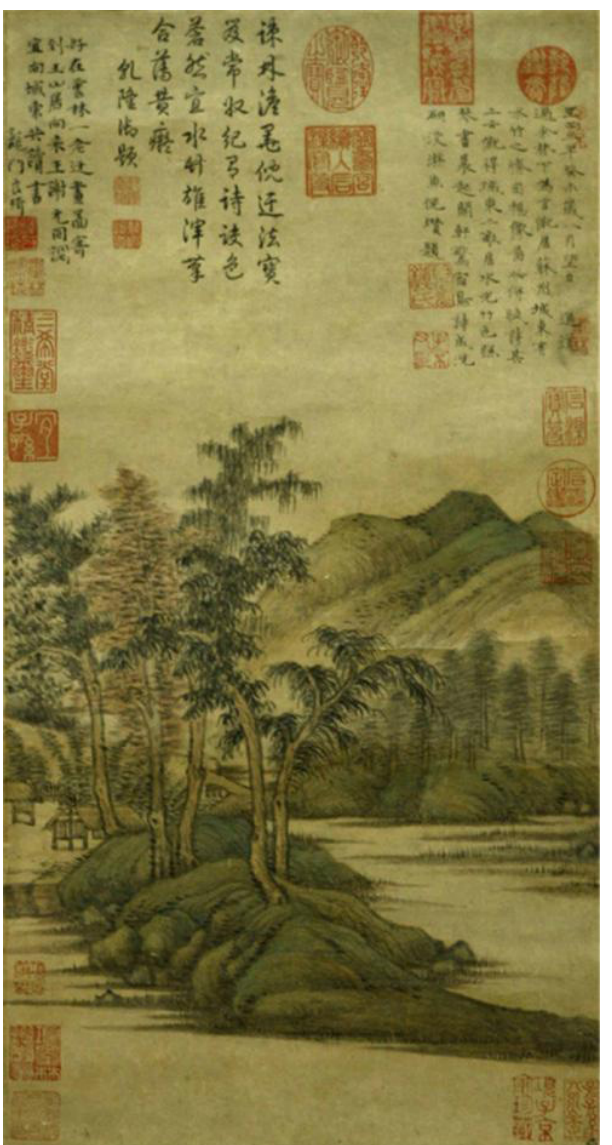

Figure 7. Ni Zan, Water and Bamboo Dwelling (Dated 1343; Hanging scroll, ink on paper, $53.5 \times 28.2 \mathrm{~cm}$; National Museum, Beijing)

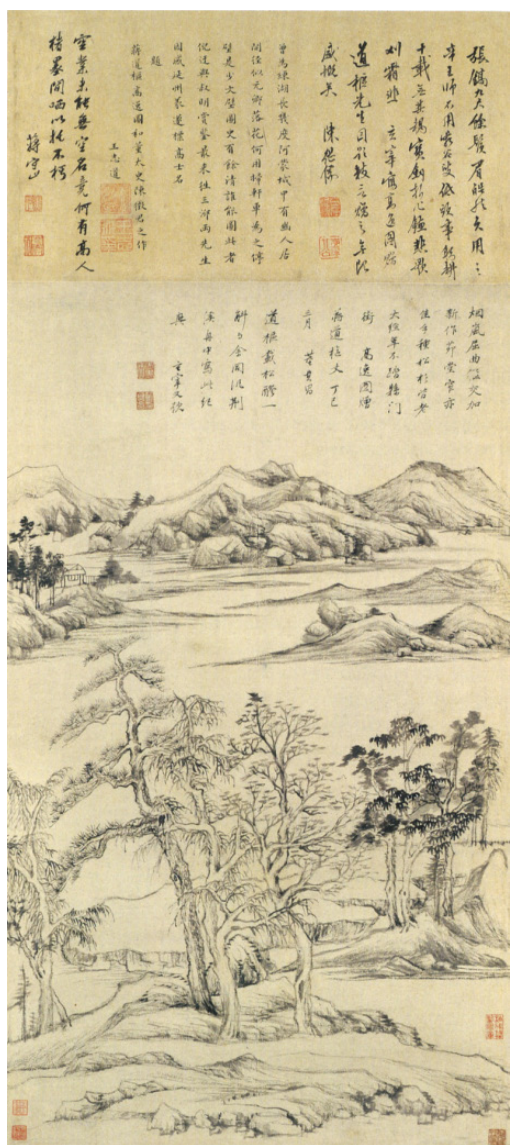

Figure 8. Dong Qichang, Hermitage (Dated 1617; Hanging scroll, ink on paper, $89.4 \times 52 \mathrm{~cm}$ ) 
There are no historical materials to know how Ni Zan learned to paint, although it is probable that he imitated ancient paintings he collected in the "Pure and Secluded Pavilion", library-studio during his wealthy life phase. For example, Enjoying the wilderness (Figure 6) is informed by another of the Four Masters of Yuan: Huang Gongwang (1269-1354). Huang's painting style was a continuation of that of the Sung dynasty when the painters were concerned with "form likeness". In this early work of $\mathrm{Ni}$, the rocks are shaped with sophisticated brushworks, and he prudently depicts the physical likeness of a variety trees, which shows an intent towards objective representation. Although Ni Zan claimed he did not care about the realistic representation of nature, the consciousness of detecting objects in a precise and masterful manner still exists in his works in a mature style. In his later-period painting The Rongxi Studio (Figure 2), Ni emphasises rigid rocks and a sloping ground in resolutely turned L-shaped brushstrokes, called folded-belt or Zhe-dai strokes. This kind of elegantly sparing stroke is a great example of the idea "love ink like gold" popularised between Chinese scholars, and Ni's use of it shows that he thought logically when he doing every stroke. Accordingly, it is automatic to contemplate the physical likeness and real structure of different objects.

The brushwork of Ni Zan is a key attribute that allows his painting to achieve wide range of effects. He advocated combining ancient and modern texture methods in line with the features of items. The Two Rocks in Figure 9 were rendered in ancient techniques involved to ax-cut, T-shaped and "horse-teeth" strokes, and he furthermore developed them with a modern free hand to avoid any stiff or unsuitable effect. In addition, this advocacy is noticeable in Ni's theory of painting outlined in the Painting Manual. In one inscription on the left of the work in Figure 10 he wrote detailed comments: "For the larger tree the brushwork should be soft, so that its branches look tender; for the smaller tree the brushwork should be ancient, so that it looks archaic. ... if the trees are seen on a sunny day, then they should be matched with sunny bamboo. This means the bamboo leaves should all point upward." Ni Zan is definitely a master, organising protean brushstrokes to catch the likeness of items; and it is on this premise that he successfully creates such spartan images. Looking at the imitations of Ni in the Ming and Qing dynasty, hardly any other painter was represented as much as Ni nor overcame his simplicity of style and individualism of spirit, although his style was widely copied as a model of orthodox culture.

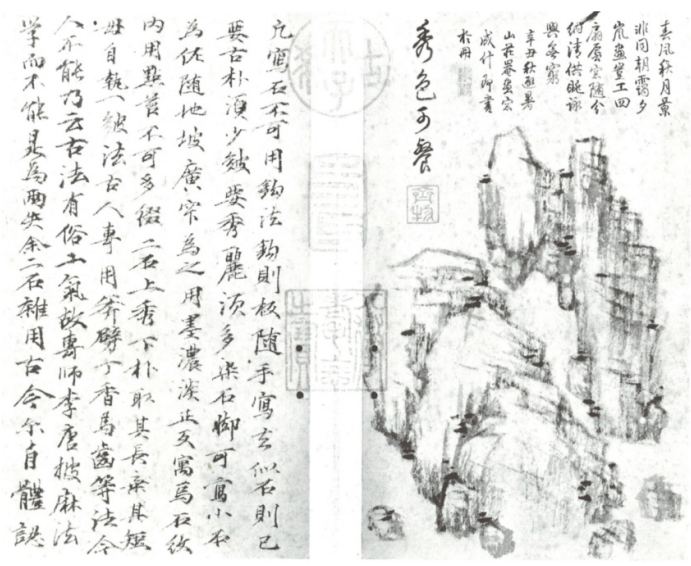

Figure 9. Anonymous, after Ni Zan, "Two Rocks", Album leaf 8 of Painting Manual

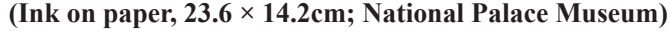

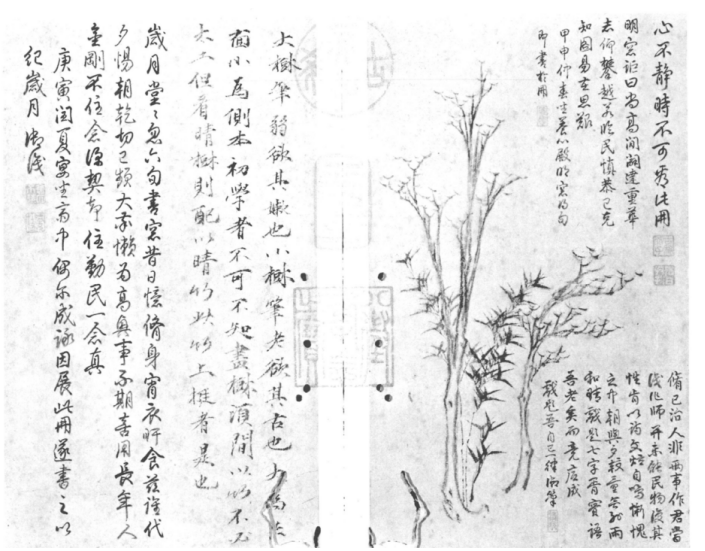

Figure 10. Anonymous, after Ni Zan, "Two Trees", Album leaf 2 of Painting Manual (Dated 1350; Ink on paper; National Palace Museum, Taipei) 
Admittedly, it seems like a contradiction that we observe the "physical likeness" that appears in Ni Zan's painting while associating his aesthetics with "not resembling". However, if we chose a positive connotation of bu-si as "beyond representation" or "more than likeness", it more accurately interpret the intention of Ni Zan. On the one hand, on the premise of "physical likeness", he emphasises "self-expression" in his painting. From this point, the reason for the uncorrelated inscription and painting, discussed above, can be explained: Ni projects his own thoughts and feelings into the characteristics of his painting, including the fond remembering of friendships, the memory of his deceased wife and the spirit of a recluse. On another hand, what to make of the elegantly sparse style of Ni's painting is not only the talented techniques but also the legend of him. Under the oppression of the foreign regime, Ni experienced a turbulent life-from being extremely wealthy to becoming a refugee, refusing to bow to the force of Mongol government - unique experiences which cultivated his outstanding qualities, evidenced by comments from Biographies of Worthies of Chin-ling dated 1550s. The later individualistic painters showed the devotion for Ni's personal qualities in their imitation works, but most of them merely depicted the dry and desolate feeling of his style and still clearly did not capture his noble spirit.

\section{Conclusion}

As early as the Tang dynasty, the art critic Zhang Yanyuan (fl.ca.mid-9th century) stated "if a painter had only sought for breath-resonance (shen-yun) in his painting, formal likeness (xing-si) would be present in his work.", and suggested painters pursue styles beyond formal likeness. Until the Sung dynasty, painters were devoted to seizing the inner reality of the visible world but derailed themselves from seeking only the appearance of objects. Subsequently, the Yuan dynasty witnessed a shift in Chinese painting from objective representation to symbolic self-expression. It is a one-sided statement to clam that Ni Zan's painting, as the typical of this period, are merely "not resembling". It is also a misunderstanding to equate the idea $b u$-si with abstractionism. In reality, he extracted manners from the earlier masters and referenced brushstrokes learned from calligraphy, capturing the appearance of reality, which are no means less proficient than the works of the Sung masters. In the meantime, convening the inner landscape of his mind and heart thus opened up a new realm of Chinese landscape painting with his lofty recluse spirit. Ultimately, Ni Zan's painting is the epitome of qi-yun-sheng-dong, which means "a good painting should be vital in its 'breath' (both personal and representational), harmonious, alive, and full of motion in its execution."

\section{References}

[1] Jin Li. Ni Zan and his associates. Vancouver: The University of British Columbia; 1998.

[2] Wen C. Fong. Beyond Representation: Chinese painting and calligraphy 8th-14th century. New York: Metropolitan Museum of Art; 1992.

[3] Wen C. Fong. Images of the Mind. Princeton: Princeton University Press; 1984.

[4] Li Shi, ed. Paintings of the Ming and Qing Dynasty. Hong Kong: Commercial Press; 2015.

[5] Zhong Hui. The Study of Shen Zhou's Landscapes in the Style of Ni Zan. Nan Jing; 2002.

[6] James Cahill. Hills Beyond a River: Chinese Painting of the Yuan Dynasty. New York: Weatherhill; 1976. 